\title{
Menopause Symptoms, Complications and Preventive Methods: An Exploratory Assessment of Awareness Among 40 to 60 Years Age Women in District Hattian Bala
}

\author{
Attiya Hameed Khan ${ }^{1, ~ *, ~ T a h i r a ~ A m j a d ², ~ F a r a h ~ T a b a s s a m ~}{ }^{1}$, Sadaf Jamil ${ }^{1}$, Mohsin Hameed Khan ${ }^{3}$, \\ Adnan $\mathrm{Shah}^{4}$ \\ ${ }^{1}$ Department of Public Health, Armed Forces Post Graduate Medical Institute Affiliated with National University of Medical Sciences, \\ Rawalpindi, Pakistan \\ ${ }^{2}$ Department of Community Medicine, Foundation University, Islamabad, Pakistan \\ ${ }^{3}$ Department of Vetrinary Sciences, Pir Mehar Ali Shah Arid Agriculture University, Rawalpindi, Pakistan \\ ${ }^{4}$ Department of Cardiac Perfusion, Bashir Medical Institute, Islamabad, Pakistan \\ Email address: \\ Attiyahameed864@gmial.com (A. H. Khan), tahiraamjad58@gmail.com (T. Amjad), Farahkhan687@gmail.com (F. Tabassam), \\ sadafradiology@gmail.com (S. Jamil), Mohsinhameedkhan1@gmail.com (M. H. Khan), Adnan.shah9930@gmail.com (A. Shah) \\ ${ }^{*}$ Corresponding author \\ To cite this article: \\ Attiya Hameed Khan, Tahira Amjad, Farah Tabassam, Sadaf Jamil, Mohsin Hameed Khan, Adnan Shah. Menopause Symptoms, \\ Complications and Preventive Methods: An Exploratory Assessment of Awareness Among 40 to 60 Years Age Women in District Hattian \\ Bala. Central African Journal of Public Health. Vol. 6, No. 4, 2020, pp. 226-231. doi: 10.11648/j.cajph.20200604.17
}

Received: July 5, 2020; Accepted: July 25, 2020; Published: August 13, 2020

\begin{abstract}
This study shows to identify the awareness level regarding symptoms and complications of menopause among Women and to determine their knowledge regarding prevention of complications of menopause. It also identify the gaps if any, in their knowledge regarding prevention of complications of menopause and give viable recommendations for creating awareness about menopause and its management in women. It was Descriptive cross-sectional study and conducted over a period of 6 months, from August 2018 to January, 2019 in the villages of District Hattian Bala. Data was collected through structured questionnaire which contain both open and close ended questions. The questions were used for the assessment of awareness of respondent regarding menopause, its symptoms, complications and preventive methods among the women in menopause age group 40-60 years. Sample was collected by using multistage probability sampling method. SPSS was used for Statistical analysis of the data. The mean age of women was, (49.59 \pm 5.712$)$ years, the mean age of menarche was, $(14.32 \pm .474)$ years, the mean age at menopause was, $(42.54 \pm 1.191)$ years. Majority of respondent had known about menopause. 297 (99\%) knew about menopause, those women who knows about the preventive and curative measures about menopause were $261(87 \%)$. (70\%) women of menopausal age group were aware regarding the common medical complications associated with menopause. 117 (39.0), of respondent get information from lady health workers, 39 (13.3\%) from lady health visitor, $44(14.67 \%)$ from friends / relatives and $38(12.7 \%)$ from electronic media. The results show that awareness regarding menopause and its symptoms has significant positive correlation with awareness regarding common medical complications associated with menopause $(\mathrm{r}=.34, \mathrm{p}<.01)$ and significant positive correlation also with awareness among respondents regarding preventive methods to overcome the complications $(\mathrm{r}=.18, \mathrm{p}<.01)$. The values of Pearson Product Moment Correlation also indicate that strong positive correlation exist between awareness regarding common medical complications associated with menopause and awareness among respondents regarding preventive methods to overcome the complications $(\mathrm{r}=.23, \mathrm{p}<.01)$. It is concluded that menopause is a natural process and it is not a disease, but it has pestiferous effects on women who are in the menopause age due to the destitution of knowledge and awareness. To abate these effects among postmenopausal women, education and medical discussion is necessary. By the results of our study which shows that most of the respondent had a knowledge regarding menopause its symptoms, complications and preventive methods. Education level also had a strong positive correlation exist between awareness regarding menopause its symptoms complications and preventive methods.
\end{abstract}


Keywords: Menopause, Awareness, Complications, Knowledge, Preventive Methods

\section{Introduction}

In women life menopause is an transitional developmental phase. According to the World Health Organization (WHO) menopause is the permanent cessation of menstruation cycle as a result of the loss of ovarian activity [1]. Natural menopause can be perceived after twelve months or more than of menorrheal period. That is not associated with a pathological cause and it is a normal physiological changes experienced by middle aged women [2].

Women regarding the age of accomplish menopause and the demonstration of menopausal signs and symptoms [3]. It is accepted that the mean age of menopause through worldwide appraisal ranges from 45 to 55 years [4]. But it is normally accepted that the mean age at menopause is about 49 years in developed countries but data were inconsistent for the underdeveloped countries because of methodological problem WHO, 1996 [5].

Women awareness of menopause is various based on multiple factors, their age, the number of birth, social, economic, cultural and education status, and geographical factors [6]. Most of women reach menopause age without having adequate knowledge about the events of this period and the ways to deal with the phenomena [7]. In the societies where women had high information about menopause, they had more knowledge about menopause. When women were well versed in the symptoms and complications of menopause [8], they were able to tolerate its complication in a better manner and prevent occurrence of its serious and irreversible consequences through appropriate treatment [9]. Menopause is an event in life, not a disease. It is a single event in a women life her last menstrual period [10]. Menarche heralds the onset of reproductive function, and menopause signals its end. With increase in life expectancy throughout the world most of the women will live through menopause. Therefore, they should have knowledge about the effects of menopause and its prevention.

\subsection{Importance of Study}

The current study had assessed the women awareness level about symptoms and complications of menopause and method of their prevention. Menopause is a natural process but due to the lack of knowledge and awareness most of the women are not able to share the problems of post menopausal stage. Under privileged areas women have low knowledge regarding these problems. There is no previous study conducted in Azad Kashmir specially District Hattian Bala, and through this study the women of villages got knowledge about these problems and we should also remove those gaps in women to give recommendations and provide interventions for improving the quality of life.

\subsection{Abbreviations}

AFPGMI: Armed Forces Post Graduate Medical Institute,
AMC: Awareness regarding Menopause and its complications, AMP: Awareness of menopause, APM: Awareness regarding menopause and its preventive methods, HRT: Hormonal replacement therapy, LE: Level of Education, LHV: Lady Health visitor, LHW: Lady Health worker, MPH: Masters in Public Health, MS: Marital Status, MS: Masters in Science, NUMS: National University of Medical Science, QOL: Quality of life, SD: Standard Deviation, SOI: Source of information WHO: World health organization.

\section{Material and Methods}

Study was conducted over a period of 6 months, from August 2018 to January, 2019 in the villages of Tehsil Hattian Bala. Data was collected through structured questionnaire which contain both open and close ended questions. The questions were used for the assessment of awareness of respondent regarding menopause, its symptoms, complications and preventive methods among the women in menopause age group 40-60 years. Sample was collected by using multistage sampling method. Tehsil Hattian consists of twelve union councils and each union council having 9-14 villages. By simple random sampling method union council Chaq Hama was selected which has 12 villages. From this union council every third village was selected by using systematic random sampling method. Villages selected were garthama, Batangi, Cham and Nardagian. By non probability convenient sampling method 75 participants from each area were selected making sample size for 300 . SPSS was used for Statistical analysis of the data. The study was conducted after obtaining approval from Institutional review board of AFPGMI (Armed Forces Postgraduate Medical Institute). Verbal informed Consent was also taken from the participant. The information gathered in these questionnaires revolves around the Assessment of women awareness level about the symptoms and complications of menopause.

\section{Results}

A total of 300 respondents from Tehsil Hattian Bala were included in the study. They were interviewed and the responses were recorded on the questionnaire.

Table 1. Socio Demographic characteristics of the respondents $(n=300)$.

\begin{tabular}{lll}
\hline Characteristics & Mean & \pm Standard deviation $( \pm$ SD) \\
\hline Age (years) & 49.59 & 5.712 \\
Age at menarche (years) & 14.32 & .474 \\
Age at Menopause (years) & 42.54 & 1.191 \\
\hline
\end{tabular}

\begin{tabular}{lll}
\hline & Frequency (n) & Percentage (\%) \\
\hline Level of education: & & \\
Uneducated & 105 & 35 \\
Primary & 125 & 41.7 \\
Matriculation & 65 & 21.7 \\
Higher education & 5 & 1.7 \\
Marital status & & \\
\hline
\end{tabular}




\begin{tabular}{lll}
\hline & Frequency (n) & Percentage (\%) \\
\hline Married & 195 & 65.0 \\
Unmarried & 22 & 7.04 \\
Divorced & 21 & 7.0 \\
Widow & 62 & 20.66 \\
\hline
\end{tabular}

Table 1. illustrate the mean age of 300 respondents was $49.59 \pm 5.712$, mean age of menarche and menopause was $14.32 \pm .474$ and $42.54 \pm 1.191$ respectively. A perception of respondents about menopause age was $42.28 \pm 1.240$ years.

Table 2. Frequency and percentages of respondents for awareness and symptoms of menopause $n=300$.

\begin{tabular}{lll}
\hline Statements & Yes n, (\%) & No n (\%) \\
\hline Knownmenopause & $297(99.0)$ & $3(1.0)$ \\
Preventive or curative measure & $261(87.0)$ & $39(13.0)$ \\
Menopause natural process/ disease & $298(99.3)$ & $2(.7)$ \\
Hot flushes & $266(88.7)$ & $34(11.3)$ \\
Night sweats & $228(76.0)$ & $72(24.0)$ \\
Sweating & $163(54.3)$ & $137(45.7)$ \\
Feeling anxious ornervous & $181(60.3)$ & $119(39.7)$ \\
Feeling depressed, down or blue & $172(57.3)$ & $122(42.6)$ \\
Impatience with other people & $206(68.7)$ & $128(42.7)$ \\
Willing to be alone & $161(53.7)$ & $139(46.3)$ \\
Flatulence (wind) or gas pains & $179(59.7)$ & $121(40.3)$ \\
Aching muscles and joints & $189(63.0)$ & $111(37.0)$ \\
Feeling tired or worn out & $163(54.3)$ & $137(45.7)$ \\
Aches in back of neck or head & $177(59.0)$ & $123(41.0)$ \\
Difficulty in sleeping & $174(58.0)$ & $126(42.0)$ \\
Decrease in stamina & $173(57.7)$ & $127(42.3)$ \\
Drying skin & $190(63.3)$ & $110(36.7)$ \\
Facial hair & $207(69.0)$ & $93(31.0)$ \\
Weight gain & $189(63.0)$ & $111(37.0)$ \\
Changes in appearance, texture or tone of skin & $196(65.3)$ & $104(34.7)$ \\
Low backache & $189(63.0)$ & $111(37.0)$ \\
Frequent urination & $181(60.3)$ & $119(39.7)$ \\
Involuntary urination when laughing or coughing & $208(69.3)$ & $92(30.7)$ \\
\hline
\end{tabular}

Table 2 Shows that, out of 300 women, 297 (99\%) knew about menopause, Those women who knows about the preventive and curative measures about menopause were $261(87 \%)$.

Table 3. Frequency and Percentages of Awareness regarding common medical complications associated with Menopause: $(n=300)$.

\begin{tabular}{lll}
\hline Statements & Yes n, (\%) & No n, (\%) \\
\hline Menopause can lead to a heart disease. & $235(78.3)$ & $65(21.7)$ \\
Menopause can lead to weakness /fracture of bones & $259(86.3)$ & $41(13.7)$ \\
Menopause can lead to obesity & $193(64.3)$ & $107(35.7)$ \\
Menopause can lead to urinary problems & $202(67.3)$ & $98(32.7)$ \\
Menopause can lead to sexualproblems & $175(58.3)$ & $125(41.7)$ \\
\hline
\end{tabular}

Table 3 Illustrate that, there are some common medical complications of menopause which shows that Menopause can lead to heart diseases $235(78.3 \%)$, weakness /fracture of bones $259(86.3 \%)$, obesity $193(64.3 \%)$, urinary problems $202(67.3 \%)$ and menopause can lead to sexual problems 175 (58.3\%).

Table 4. Frequency and percentages of Awareness level among respondent regarding preventive method $n=300$.

\begin{tabular}{llr}
\hline Statements & Yes, $\mathbf{n}(\%)$ \\
\hline a. For reducing hot flashes & No, n (\%) \\
Avoid eating hot and spicy meals & $196(65.3)$ \\
Avoid hot and crowded places & $193(64.3)$ \\
Wearing several thin shirts in winter & $178(59.3)$ & $102(34.7)$ \\
Avoid drinking coffee & $201(67.0)$ \\
Having deep breathes during hot flushes & $211(70.3)$ \\
b. Reducing the other complications & $107(35.7)$ \\
Drink one glass of milk or yogurt before going to bed & $219(73.0)$ \\
Sleep properly (8 hours) and perform daily activities & $200(66.7)$ \\
Read the newspaper daily (improving the memory) & $109(36.3)$ \\
Milk, yogurt, and cheese in routine & $89(29.7)$ \\
\hline
\end{tabular}




\begin{tabular}{lll}
\hline Statements & Yes, $\mathbf{n}(\mathbf{\%})$ & No, $\mathbf{n}(\mathbf{\%})$ \\
\hline Exercise every day & $139(46.3)$ & $161(53.7)$ \\
Take calcium tablet or syrup & $225(75.0)$ & $75(25.0)$ \\
c. For Routine checkups & & $204(68.0)$ \\
Annual mammography & $96(32.0)$ & $88(29.3)$ \\
Take general medical examination & $212(70.7)$ & $170(43.3)$ \\
Go for Pap smear and get the pelvis examination & $130(43.3)$ & $46(15.3)$ \\
Visit doctors in case of having vaginal bleeding & $254(84.7)$ & \\
\hline
\end{tabular}

Table 4. Illustrate that, according to the result of the study which shows that there are some preventive methods to overcome the complication of menopause those women who had knowledge regarding the preventive methods to overcome the complications were, firstly for reducing of hot flashes, Avoid eating hot and spicy meals were the 196 (65.3).

Table 5. Frequency and percentage of the sources of information $n=300$.

\begin{tabular}{lll}
\hline Source & Frequency & Percentage (\%) \\
\hline Doctor & 44 & 14.67 \\
Lady health visitor (LHV) & 39 & 13.0 \\
Lady health worker (LHW) & 117 & 39.0 \\
Print media & 18 & 6.0 \\
Electronic media & 38 & 12.7 \\
Friends / relatives & 44 & 14.67 \\
\hline
\end{tabular}

Table 5 shows that those women who get information from doctors were 44 (14.67), LHV 39 (13.3), LHW 117 (39.0), Print media 18 (6.0), Electronic media 38 (12.7) and friends/ relatives were 44 (14.67).

Correlation Matrix:

Table 6. Correlation Matrix of awareness regarding menopause and its symptoms, awareness regarding common medical complications associated with menopause, awareness among respondents regarding preventive methods to overcome the complications $(n=300)$.

\begin{tabular}{llll}
\hline Scales & $\mathbf{1}$ & $\mathbf{2}$ & $\mathbf{3}$ \\
\hline AMS & $1 * *$ & $.34^{* *}$ & $.18^{* *}$ \\
ACMC & - & $1 * *$ & $.23 * *$ \\
APM & - & - & $1 * *$ \\
\hline
\end{tabular}

Note. AMS=Awareness Regarding Menopause and Its Symptoms, ACMC $=$ Awareness Regarding Common Medical Complications Associated With Menopause, APM=Awareness Regarding Preventive Methods to Overcome the Complications $(* * \mathrm{p}<.01)$.

Table 7. Correlation Matrix of awareness regarding menopause and its symptoms, awareness regarding common medical complications associated with menopause, awareness among respondents regarding preventive methods to overcome the complications and marital status $(n=300)$.

\begin{tabular}{lllll}
\hline Scales & $\mathbf{1}$ & $\mathbf{2}$ & $\mathbf{3}$ & $\mathbf{4}$ \\
\hline AMS & $1 * *$ & $.34^{* *}$ & $.18^{* *}$ & -.03 \\
ACMC & - & $1 * *$ & $.23 * *$ & -.04 \\
APM & - & - & $1 * *$ & .01 \\
MS & - & - & - & $1 * *$ \\
\hline
\end{tabular}

Note. AMS=Awareness Regarding Menopause and Its Symptoms, ACMC $=$ Awareness Regarding Common Medical Complications Associated With Menopause, APM=Awareness Regarding Preventive Methods To Overcome The Complications, MS=Marital Status $(* * \mathrm{p}<.01)$.
Table 8. Correlation Matrix of awareness regarding menopause and its symptoms, awareness regarding common medical complications associated with menopause, awareness among respondents regarding preventive methods to overcome the complications and level of education $(n=300)$.

\begin{tabular}{lllll}
\hline Scales & $\mathbf{1}$ & $\mathbf{2}$ & $\mathbf{3}$ & $\mathbf{4}$ \\
\hline AMS & $1^{* *}$ & $.34^{* *}$ & $.18^{* *}$ & $.13^{*}$ \\
ACMC & - & $1^{* *}$ & $.23^{* *}$ & $.14^{*}$ \\
APM & - & - & $1 * *$ & $.14^{*}$ \\
LE & - & - & - & $1{ }^{* *}$ \\
\hline
\end{tabular}

Note. AMS $=$ Awareness Regarding Menopause and Its Symptoms, $\mathrm{ACMC}=$ Awareness Regarding Common Medical Complications Associated With Menopause, APM=Awareness Regarding Preventive Methods To Overcome the Complications, $\mathrm{LE}=$ level of education $\left(* * \mathrm{p}<.01,{ }^{*} \mathrm{P}<.05\right)$.

Table 9. Correlation Matrix of awareness regarding menopause and its symptoms, awareness regarding common medical complications associated with menopause, awareness among respondents regarding preventive methods to overcome the complications and source of information $(n=300)$.

\begin{tabular}{lllll}
\hline Scales & $\mathbf{1}$ & $\mathbf{2}$ & $\mathbf{3}$ & $\mathbf{4}$ \\
\hline AMS & $1 * *$ & $.34^{* *}$ & $.18^{* *}$ & .05 \\
ACMC & - & $1 * *$ & $.23^{* *}$ & .04 \\
APM & - & - & $1 * *$ & -.01 \\
SOI & - & - & - & $1 * *$ \\
\hline
\end{tabular}

Note. AMS $=$ Awareness Regarding Menopause and Its Symptoms, ACMC $=$ Awareness Regarding Common Medical Complications Associated With Menopause, APM=Awareness Regarding Preventive Methods to Overcome the Complications, $\mathrm{SOI}=$ Source of Information $(* * \mathrm{p}<.01)$.

\section{Discussions}

Menopause is an event in life it's not a disease. It is a single event in a woman's life and her last menstrual period. Menarche heralds the onset of reproductive function and menopause signals its end. With increase in life expectancy throughout the world most of the women will live through menopause. Therefore, they should have knowledge about the menopause and health effects of menopause and its preventive methods regarding menopause. The present study was to assess the knowledge and awareness regarding menopause, its symptoms, complications and preventive methods among the women of age 40-60 years. The aim of this study was to improve the level of awareness among menopausal women and provide interventions for improving the quality of life of those menopausal women of Tehsil Hattian Bala Azad Jammu \& Kashmir.

The attitudes of women to menopause are strongly influenced by social, cultural and economic settings in which they live and may also reflect the differences in modes of treatment for or perceptions of its symptoms [11]. Menopausal symptoms are observed in all countries of the world but prevalence varies from society to society. [12]. Hot flushes and 
night sweating is the commonest climacteric symptom experienced in Caucasian population [13]. Some studies show that education had a strong association with menopause, its awareness, symptoms and preventive methods [14]. Women who had education level of matriculation or who had a higher education had a good knowledge regarding menopause and its symptoms as compared to those women who were uneducated but our study did not show any significant association between education and awareness level of menopause. By the results of our study it was found that (35\%) were uneducated,(41.7\%) were at the primary level $(21.7 \%)$ were at the matriculation level and only (1.7\%) were at the higher level which shows that education level of the respondent was not good because very few women get the matriculation level of education and higher education level. Our study shows that mostly women were uneducated [15]. But the awareness level regarding menopause and its symptoms, complications and preventive methods were good as compared to other study [16], which shows that education had a significant association with awareness level of menopause. show that education level of women (uneducated, with primary level education, matriculated, having higher education) has strong positive correlation between awareness regarding menopause and its symptoms $(\mathrm{r}=.13, \mathrm{p}<.05)$ and also a strong positive correlation with awareness regarding common medical complications associated with menopause $(\mathrm{r}=.14, \mathrm{p}<.05)$ as well as with awareness among respondents regarding preventive methods to overcome the complications $(\mathrm{r}=.14, \mathrm{p}<.05)$.

\subsection{Recommendation for Future}

It is considerable to animate educational institutions, medical care providers and the health department to educate the women about menopause, its symptoms, complications, long term effects and treatment options. This combined accomplishment by educational programs and health care providers will help in access public awareness. Health care professionals should understand women attitude regarding the menopause in order to give desirable information and help to create positive attitudes and healthy perceptions of the menopause and the coping methods. A study should be carried out on psycho educational program for improving women attitude and opposing with menopause symptoms. Counsel able activities of premenopausal, menopausal and post menopausal women need to be familiarized and facilities should be made available to those who need them.

\subsection{Limitation of the Study}

\subsubsection{Effectiveness of the Study}

It was a community base study which was conducted by the validated questionnaire. Through this study we had raised the awareness level regarding menopause, its symptoms, complications and preventive measure among menopausal women in rural area.

This study also provides interventions among women of menopause age group to overcome the complications of menopause for improving the quality of life in post menopausal stage. It will be included in literature review for comparing and analyzing the new studies of same subject.

\subsubsection{Lacks of the Study}

It had limited sample size and it was not consist of different stages of menopause. It was only consist of 40-60 years old aged women of menopause stage, we had only focused on symptoms, complications and preventive measures but did not calculate the risk factors which may be lead to menopausal symptoms.

\section{Conclusion}

Menopause is a natural process and it is not a disease, but it has pestiferous effects on women who are in the menopause age due to the destitution of knowledge and awareness. To abate these effects among postmenopausal women, education and medical discussion is necessary. By the results of our study which shows that most of the respondent had a knowledge regarding menopause its symptoms, complications and preventive methods. Education level also had a strong positive correlation exist between awareness regarding menopause its symptoms complications and preventive methods.

\section{Conflict of Interest Statement}

We hereby confirm that there is no conflict of interest associated with publication.

\section{Acknowledgements}

I pay my gratitude to my family who stood by me and spared me for this uphill task. Their continuous support, prayers and sacrifices remained a source of inspiration for me in completion of my study project.

I am indebted to my supervisor Dr Tahira Amjad, Assistant professor at foundation medical university who has always been very considerate and encouraging despite knowing my academic misdemeanors.

\section{References}

[1] Chuni N, Sreeramareddy CT. Frequency of symptoms, determinants of severe symptoms, validity of and cut-off score for Menopause Rating Scale (MRS) as a screening tool: a cross-sectional survey among midlife Nepalese women. BMC women's health. (2011) 11-30.

[2] Rahman SASA, Zainudin SR, Mun VLK. Assessment of menopausal symptoms using modified Menopause Rating Scale (MRS) among middle age women (2010) 109-14.

[3] Cauley JA, Robbins J, Chen Z, Cummings SR, Jackson RD, LaCroix AZ, et al; Women's Health Initiative Investigators. Effects of estrogen plus progestin on risk of fracture and bone mineral density: the Women's Health Initiative randomized trial. JAMA. 2003; 290: 1729-38. [PMID: 14519707]. 
[4] Bener A, Rizk DE, Shaheen H, Micallef R, Osman N, Dunn E. Measurement-specific quality-of-life satisfaction during the menopause in an Arabian Gulf country. Climacteric 2000; 3 (1): 43-9.

[5] Lund KJ. Menopause and the menopausal transition. Med Clin North Am 2008; 92 (5): 1253-71.

[6] Yaffe K, Vittinghoff E, Ensrud KE, Johnson KC, Diem S, Hanes V, et al. Effects of ultra-low-dose transdermal estradiol on cognition and health-related quality of life. Arch Neurol. 2006; 63: 945-50. [PMID: 16831962].

[7] Leon P, Chedraui P, Hidalgo L, Ortiz F. Perceptions and attitudes toward the menopause among middle aged women from Guayaquil, Ecuador. Maturitas. 2007; 57 (3): 233-238.

[8] Moilanen J, Aalto A-M, Raitanen J, Hemminki E, Aro AR, Luoto R. Physical activity and change in quality of life during menopause - an 8-year follow-up study. Health Qual Life Outcomes. 2012 Jan 23; 10: 8.

[9] Malik HS. Knowledge and attitude towards menopause and hormone replacement therapy (HRT) among postmenopausal women. J Pak Med Assoc 2008; 58: 164-167.

[10] Leon P, Chedraui P, Hidalgo L, Ortiz F. Perceptions and attitudes toward the menopause among middle aged women from Guayaquil, Ecuador. Maturitas. (2007) 41 (4): 269-274.

[11] Sagdeo M, Arora D. Menopausal symptoms: A comparative study in rural and urban women. JK Science. (2011); 6 (2): 36-45.

[12] Nisar N, Sohoo NA. Frequency of menopausal symptoms and their impact on the quality of life of women: a hospital based survey. JPMA. (2009) 59: 752-756.

[13] Richard-Davis G, Wellons M. Racial and ethnic differences in the physiology and clinical symptoms of menopause. SeminReprod Med 2013; 31: 380-386.

[14] Shea JL. Chinese women's symptoms: relation to menopause, age and related attitudes. Climacteric 2006; 9: 30-39.

[15] Holmes-Rovner M, Padonu G, Kroll J, Breer L, Ronver DR, Talarczyk G, et al. African-American women's attitudes and expectations of menopause. Am J Prev Med 1996; 12: 420 423.

[16] Women's Health Initiative Investigators. Risks and benefits of estrogen plus progestin in healthy postmenopausal women: principal results from the Women's Health Initiative randomized controlled trial. JAMA. (2002).

[17] Wong LP, Ah NL. A Survey of Knowledge and Perceptions of Menopause among Young to iddle-Aged Women in Federal Territory, Kuala Lumpur, Malaysia. Journal of the University of Malaya Medical Centre (JUMMEC). (2007).

[18] Tuomikoski P, Ylikorkala O, Mikkola TS. Menopausal hot flushes and vascular health. (2011).

[19] Bindhu SA. Climacteric symptoms among women in a rural area in Kerala. Journal of Evolution of Medical and Dental Sciences. (2018).

[20] Brantelid IE, Nilvér H, Alehagen S. Menstruation during a lifespan: a qualitative study of women's experiences. Health care for women international. (2017). 